\title{
AN UNUSUAL VARIATION OF OESOPHAGEAL ATRESIA
}

BY

\author{
JAMES LISTER \\ From the Nuffield Department of Paediatric Surgery, Institute of Child Health, University of London, \\ and the Queen Elizabeth Hospital for Children, London
}

(RECEIVED FOR PUBLICATION NOVEMBER 22, 1962)

Congenital anomalies of the oesophagus were once thought to be relatively rare. Plass in 1919 reported one case and in an exhaustive review of the literature found 136 fully verified cases; he stated that there was some variation in the minor details of the anomaly, but the general picture was uniform - a blind upper pouch ending at a level between the lower border of the larynx and the tracheal bifurcation and a lower oesophageal segment opening into the trachea close to the bifurcation. Plass found, but did not discuss, 17 cases where there was an oesophageal atresia with upper and lower cul-de-sacs, but no fistula to the trachea; he also found one case with a diaphragmatic occlusion to the oesophagus.

Since the work of Leven (1941) and Ladd (1944) on staged repairs and Haight and Towsley's (1943) first success with direct anastomosis there has been a great increase in the number of cases diagnosed and reported. The frequency of the variations of the anomaly remains largely unchanged; about $90 \%$ show a blind upper pouch, the distal oesophagus communicating with the trachea; about $8 \%$ have oesophageal atresia with no fistula and the remainder are the very unusual types - those with a fistula from the upper pouch to the trachea, with or without a fistula from the lower pouch, and those with a tracheo-oesophageal fistula but no atresia of the oesophagus.

One further extremely rare variation has been reported by Goldenberg (1960) and Schwartz and Dale (1955); these were cases in which the deficiency in the oesophagus was in the nature of a web obstruction with an associated fistula passing downwards and backwards from the trachea to the oesophagus distal to the web. In Goldenberg's case there was a second tracheo-oesophageal fistula above the septum. Two further cases of this rare anomaly are reported.

\section{Case Reports}

Case 1. A male child was born at home on January 20,
1962, at full term by normal delivery, birth weight $2 \cdot 27 \mathrm{~kg}$. He was the third child, with no family history of congenital anomalies. He regurgitated excessive mucoid secretions from the time of birth, and fluids given by mouth were returned. He was admitted to Pembury Hospital during his first 24 hours of life where radiographs taken after a lipiodol swallow demonstrated an oesophageal obstruction and air in the stomach indicating a tracheo-oesophageal fistula. He was transferred to the Queen Elizabeth Hospital for Children on January 21, 1962, where straight radiograph of the chest with an opaque tube in the oesophagus confirmed the diagnosis and showed that the blind upper pouch reached the level of the seventh dorsal vertebra (Fig. 1).

On admission the child was in respiratory distress and operation was delayed for 12 hours during which time the pharynx was aspirated every 15 minutes and penicillin and streptomycin were given. At operation on January 22, through a right postero-lateral thoracotomy, the mediastinum was explored. An oesophageal catheter was passed and was seen to be held up at a level just below the bifurcation of the trachea where the diameter of the oesophagus was about $1.5 \mathrm{~cm}$.; the oesophagus was firmly adherent to the trachea at this

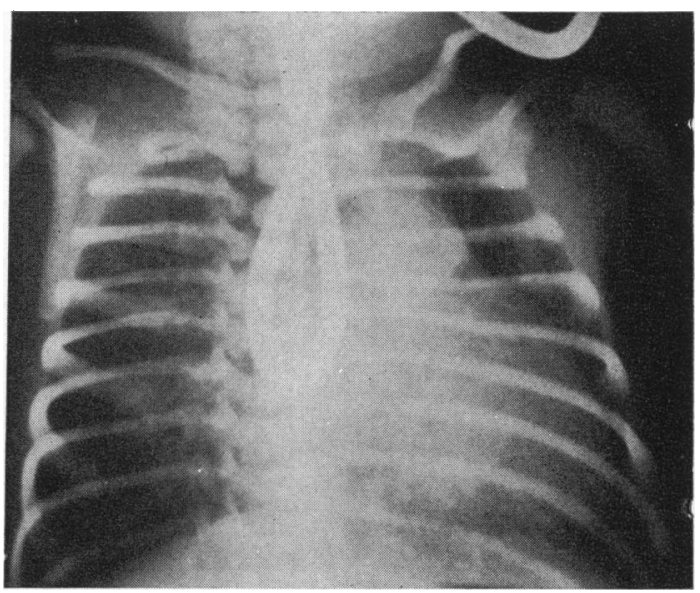

FIG. 1.-Chest radiograph of Case 1 showing opaque tube in blind upper oesophageal pouch reaching level of 7 th dorsal vertebra. 
FIG. 2.-Diagram of abnormality found in each case.

FIG. 3.-Chest radiograph of Case 2 showing opaque tube in blind upper oesophageal pouch reaching level of 5 th dorsal vertebra.

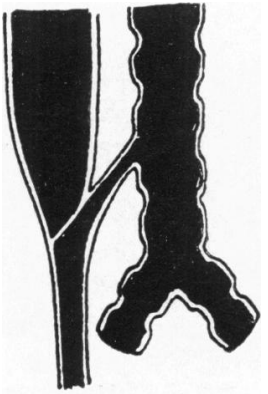

FIG. 2.

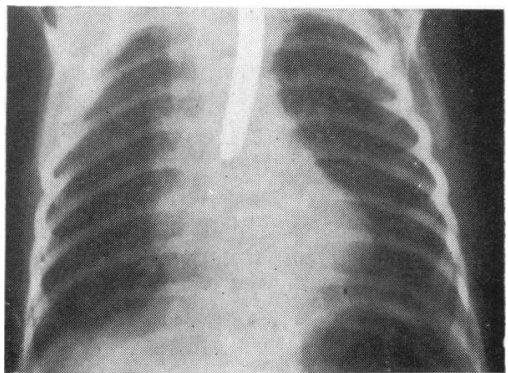

FIG. 3. level; below it the oesophagus was of normal calibre and there was no breach of continuity. The oesophagus was dissected free from the trachea and a fistula demonstrated passing downwards from the trachea, just above the carina, to the dilated part of the oesophagus; but air was seen to pass from the trachea to the lower oesophagus, and when the fistula had been divided and its tracheal end closed a probe demonstrated an oblique septum running across the oesophagus just above the fistula (Fig. 2). The oesophageal opening of the fistula was enlarged by incising the oesophagus downwards, a vertical incision made in the dilated oesophagus above, the septum incised and a transverse anastomosis made with a single layer of $5 / 0$ black silk stitches. A fine polyvinyl feeding tube was passed across the anastomosis to the stomach. The chest was closed leaving a waterseal intercostal drain.

Post-operative recovery was satisfactory, feeding by the oesophageal tube was started in 48 hours and the intercostal drain removed on the seventh day. The feeding tube was removed on the tenth day and the child fed orally without difficulty. He gained weight very slowly but there was no regurgitation or vomiting. A barium swallow demonstrated a satisfactory anastomosis and also showed a hypertrophic pyloric stenosis, but since there was no vomiting this was not treated. He was gaining weight and was swallowing well when discharged home on March 2, 1962.

Case 2. A female child of Jordanian parents was born on March 21, 1962, by a precipitate labour from a mother with a history of hydramnios (birth weight $2.045 \mathrm{~kg}$.). She was the fourth child, there being no history of congenital abnormalities in her siblings.

From the time of birth she was reported as being 'sniffly'. An attempt at breast feeding after 24 hours failed because the infant choked, and a feed of water the following day was immediately returned, though it was sucked avidly. After this feed an oesophageal tube was found to stick at $10 \mathrm{~cm}$.

She was admitted to the Queen Elizabeth Hospital for Children 48 hours after birth with a temperature of $93 \cdot 6^{\circ}$ F. $\left(34 \cdot 2^{\circ}\right.$ C. $)$, and some rhonchi at both bases. Straight radiographs demonstrated that an oesophageal catheter was stopped at the level of the fifth dorsal vertebra and there was air in the stomach (Fig. 3). After warming the infant and inserting an intravenous cannula she was taken to theatre.

Under general anaesthesia, through a right posterolateral thoracotomy, the mediastinum was explored. A tube passed down the oesophagus demonstrated the obstruction and the narrow oesophagus distal to it, but there was no break in the continuity of the oesophagus. The oesophagus was densely adherent to the trachea just above the carina and at this level a wide fistula was found between trachea and oesophagus below the obstruction. When this fistula had been divided, a very fine membranous septum was found in the oesophagus. An oblique incision was made in the oesophagus above the septum, the septum excised, and the oesophagus closed transversely, suturing the upper border of the opening made in the upper pouch to the lower border of the enlarged oesophageal opening of the tracheooesophageal fistula using $5 / 0$ black silk sutures.

After operation the infant's temperature was $93 \cdot 6^{\circ} \mathrm{F}$. $\left(34 \cdot 2^{\circ} \mathrm{C}\right.$.) and she remained apnoeic for three hours and required positive pressure respiration. For one week her post-operative course was stormy; she had several cyanotic attacks, usually associated with apnoea, and 48 hours after operation she had a mild degree of sclerema involving mainly the legs. She also had fits involving twitching of legs and arms. The apnoeic attacks did not appear to be due to respiratory obstruction, though frequent nasopharyngeal aspiration was carried out; she was given calcium gluconate together with expressed breast milk feeds through a fine feeding tube passing across the anastomosis. During this time the intercostal tube drained some serous fluid, but on the eighth post-operative day the child collapsed and was found to have a right-sided tension pneumothorax.

The chest was reopened and the lung found to be collapsed; the anastomosis showed no obvious leak, though there was some fibrinous matter around it. The chest was closed with upper and lower water-seal drains which were attached to negative pressure suction. Feeding through the trans-anastomotic tube was continued. Two days after the second operation milk was aspirated from the chest drains, but the child's general condition remained good, though she had now developed a loud systolic murmur below the left clavicle. The chest condition slowly improved and two weeks later the feed- 
ing tube was removed and the infant given feeds by mouth.

One month after the second operation the child went into acute cardiac failure with sacral oedema and collapse. This acute attack was relieved by passing a naso-gastric tube and by digitalization.

Barium swallow showed no oesophageal narrowing and no leak at the anastomosis. Investigation of the cardiac condition has not been completed.

\section{Comment}

Two points emerge from these two cases. First the low level of the blind upper pouch, reaching below the fifth dorsal vertebra in each case, was unusual and indicated that the two ends of the oesophagus were probably overlapping, since the fistula from the lower pouch usually communicates with the bronchial tree above the level of the bifurcation of the trachea at the level of the third dorsal vertebra. A very low blind upper pouch suggests, therefore, that the oesophageal atresia may be of a septal type. Secondly, the breakdown of the anastomosis in the second case was interesting: at the second thoracotomy eight days after the anastomosis had been made there was no obvious leak, no evidence of tension on the suture lines, and yet the appearance was one of an anastomosis which had been made within 24 hours. Although the child had had three doses of hydrocortisone on account of the sclerema, this had been stopped, and it seemed very likely that the failure of union was due to a poor local blood supply. The thoracotomy closure appeared to be healing normally. In each case there was considerable bleeding from a small artery crossing behind the oesophagus at the level of the web, a vessel which might have been considerably larger during development.

It is because of the additional light that the rarer anomalies throw on the embryogenesis of oesophageal atresia that these two cases are reported.

\section{Aetiology}

Many theories as to the pathogenesis of oesophageal atresia have been put forward. Mackenzie (1884) in one of the first reviews of oesophageal atresia suggested a genetic cause, citing the instance of a man who fathered two children with oesophageal atresia by different wives; but familial incidence is very rare.

Tandler (1902) demonstrated a solid stage in the development of the human duodenum and an arrest of development at a similar stage in the oesophagus has been suggested. But, although Reese (1926) showed that there was a temporary occlusion in the developing oesophagus of alligators and snakes, Johns (1952) showed that occlusion of the oesophagus was never complete in humans. In fact the narrowing of the oesophagus by proliferating epithelium is at the $20 \mathrm{~mm}$. stage, at a time when the trachea is already separated from the oesophagus, so that arrest of development at that time would not explain the frequent occurrence of the tracheooesophageal fistula.

The other main group of theories is concerned with deviation of the developing septum between the oesophagus and trachea, which could explain both the oesophageal atresia and the tracheooesophageal fistula. Shattock (1890) suggested a pulling forward of the posterior wall of the oesophagus when the trachea is budding off the anterior wall, so that the oesophageal lumen is obliterated. Rosenthal (1931) suggested that deviation was due to altered cell growth along the septum, and not to any mechanical pressures. Gruenwald (1940) suggested the deformity was due to the oesophagus remaining attached to the laryngotracheal tube and being drawn out and obliterated by the more rapidly growing laryngotracheal tube.

External pressure, causing deviation of the septum, might be due to a large cardiac anlage or to anomalous great vessels. These possibilities are, on the whole, not accepted; Rosenthal (1931) points out that there is a considerable distance between the cardiac anlage and the primary foregut in the 3-5 $\mathrm{mm}$. embryo when the disturbance is believed to occur; and the trachea, which lies closer to the cardiac anlage, is practically never involved. Rosenthal also suggests that it is more likely that blood vessels will be influenced by the development of surrounding tissues than that those tissues would be influenced by developing blood vessels; and again in the $4 \mathrm{~mm}$. embryo the aortic arches are ventral and cranial to the site of the malformation of oesophageal atresia.

However, there is no doubt that anomalous arteries are sometimes found in association with oesophageal atresia. Keith and Spicer (1906) described two cases with a right aortic arch and the left subclavian artery crossing behind the trachea just below the blind upper pouch of the oesophagus; they also described a third case with a right subclavian artery arising from a left aorta and crossing behind the trachea in a similar position. Fluss and Poppen (1951) describe three more cases of oesophageal atresia with aberrant arteries and suggest that the anomaly does not necessarily occur at the $4 \mathrm{~mm}$. stage, but might occur at the $18 \mathrm{~mm}$. stage when the aortic arches are in close proximity to the oesophagus. 


\section{- Discussion}

About $90 \%$ of all cases of oesophageal atresia fall into the group with a blind upper pouch and a fistula between the lower pouch and the trachea. Ingalls and Prindle (1949) and Ipsen and Okkels (1932) stress the common associated anomalies found in oesophageal atresia, such as duodenal atresia, imperforate anus and congenital heart disease, and suggest a generalized insult to the embryo at the critical stage of development of all these organs. But the $10 \%$ of cases which do not fall into the common group, and particularly cases like the two described here, with a simple septal obstruction and tracheo-oesophageal fistula, strongly suggest that oesophageal atresia is not always an arrest of normal development, but may be produced by some mechanical interference at a later stage. Louw (1959) showed that small intestinal atresia in the form of an occluding diaphragm could be produced by local interference with blood supply. It seems quite possible, therefore, that oesophageal atresia may have the same aetiology as intestinal atresia; the more common type, with its frequent associated anomalies, being caused by some general interference with foetal blood supply or oxygenation, such as faulty placentation, whilst the type presented here has been produced by a local interference with blood supply. The local intereference in these cases might well have been external pressure from an arteria aberrans - the remnant of the fourth right aortic arch-as was described in one of Fluss and Poppen's (1951) cases. In each case there was considerable bleeding from a small artery crossing the upper pouch of the oesophagus and the size of these vessels, of course, bears no relation to their size at the $18 \mathrm{~mm}$. stage.

\section{Summary}

Two cases of septal atresia of the oesophagus are described, and their possible bearing on the aetiology of the condition is discussed.

\section{REFERENCES}

Fluss, Z. and Poppen, K. J. (1951). Embryogenesis of tracheoesophageal fistula and esophageal atresia. Arch. Path., 52, 168. Goldenberg, I. S. (1960). An unusual variation of congenital tracheoesophageal fistula. J. thorac. cardiovasc. Surg., 40, 114.

Gruenwald. P. (1940). A case of atresia of the esophagus combined with tracheo-esophageal fistula in a $9 \mathrm{~mm}$. human embryo and with tracheo-esophageal fistula in a $9 \mathrm{~mm}$. human em

Haight, C. and Towsley, H. A. (1943). Congenital atresia of the esophagus with tracheoesophageal fistula. Surg. Gynec. Obstet., 76, 672.

Ingalls, T. H. and Prindle, R. A. (1949). Esophageal atresia with tracheoesophageal fistula; epidemiologic and teratologic implications. New Engl. J. Med., 240, 987.

Ipsen, J. and Okkels, H. (1932). Congenital esophageal atresia and esophagotracheal fistula; synchronism in origin of malformations. Hospitalstidende, 75, 1083 .

Johns, B. A. E. (1952). Developmental changes in the oesophageal epithelium in man. J. Anat. (Lond.), 86, 431 .

Keith, A. and Spicer, J. E. (1906). Three cases of malformation of the tracheo-oesophageal septum. ibid., 41, 52.

Ladd, W. E. (1944). The surgical treatment of esophageal atresia and tracheoesophageal fistulas. New Engl. J Med., 230, 625.

Leven, N. L. (1941). Congenital atresia of the esophagus with tracheoesophageal fistula. J. thorac. Surg., 10, 648.

Louw, J. H. (1959). Congenital intestinal atresia and stenosis in the newborn; observations on its pathogenesis and treatment. Ann. roy. Coll. Surg. Engl., 25, 209.

Mackenzie, M. (1884). A Manual of Diseases of the Throat and Nose, Vol. 2, p. 217. Churchill, London.

Plass, E. D. (1919). Congenital atresia of the esophagus with tracheoesophageal fistula; associated with fused kidney. Johns Hopk. Hosp. Rep., 18, 259.

Reese, A. M. (1926). The occlusion of the esophagus and trachea in crocodilia and snakes. Amer. J. Anat., 37, 195.

Rosenthal, A. H. (1931). Congenital atresia of the esophagus with

tracheo-esophageal fistula. Arch. Path., 12, 756 .
Schwartz, S. I. and Dale, W. A. (1955). Unusual tracheo-esophageal fistula with membranous obstruction of the esophagus and postoperative hypertrophic pyloric stenosis. Ann. Surg., 142, 1002.

Shattock, S. G. (1890). Congenital atresia of the oesophagus. Trans. path. Soc. Lond., 41, 87.

Tandler, J. (1902). Zur Entwicklungsgeschichte des menschlichen Duodenum in frühen Embryonalstadien. Morph. Jb., 29, 187. 